\title{
Bancarización en base al Negocio del Barrio: El Caso CajaVecina
}

\author{
José Ignacio Alarcón Molina * \\ Universidad de Chile
}

Juan Felipe Espinosa Cristia**

Universidad Andrés Bello

\section{RESUMEN}

El presente artículo describe y analiza un mecanismo de inclusión financiera llamado CajaVecina. Dicho mecanismo ha sido creado por la empresa BancoEstado. El sistema CajaVecina, se inscribe en el fenómeno conocido como la Cashless Society. El tipo de servicio se puede clasificar como una corresponsalía bancaria. La corresponsalía permite a un almacenero el disponer de un terminal POS - point of sale- el que unido a la tarjeta débito de las cuentas vista, permite a los usuarios acceder a variados servicios bancarios y de pagos, en el mismo almacén. El capítulo presenta el sistema, mostrando el éxito de su difusión y adopción, pero problematizando la relación económica-social que se presenta en las nuevas formas en que se relacionan el usuario, almacenero (intermediario) y el banco. Se utiliza un enfoque basado en la sociología del dinero, de los pagos y los estudios del nuevo institucionalismo como base para el análisis de un corpus de datos obtenido en un sitio web de reclamos de los usuarios del sistema. Se concluye mostrando al mecanismo de CajaVecina como un mecanismo del tipo corresponsalía bancaria que otorga un tipo de inclusión financiera muy distinto al de aquellos que tienen acceso a los servicios del propio BancoEstado, a través de sus oficinas y servicios más tradicionales.

Palabras clave: Caja vecina, bancarización, dinero, pago, finanzas

\section{Abstract}

The following paper describes and analyses a Chilean financial inclusion mechanism called CajaVecina from the Chilean state own BancoEstado. This mechanism falls within the phenomenon known as the Cashless Society. CajaVecina is a banking correspondent (BC) service that allows a storekeeper to have a point of sale terminal, which together with the debit card of the sight accounts, enables the users to have access to varied banking and payment services in the same store. The chapter introduces the service, showing the success of its spreading and acceptance but problematising the economic-social relationship present in the new forms in which the user, the storekeeper (intermediary) and the bank connect. The sociology of money, of payments and the studies of the neo-institutionalism are the basis for the analysis of a corpus obtained from a website with complaints from the users of the system. The conclusion shows that CajaVecina gives a kind of financial inclusion considerably different from the one of those who have access to the services of BancoEstado in its regular offices.

Keywords: Neighboring box, banking, money, payment, finance

*j.alarcon@ug.uchile.cl

** juan.espinosa@unab.cl

Los autores agradecen el patrocinio de la Universidad de Chile mediante los fondos de la Dirección de Asuntos Estudiantiles -DAE- para la iniciación de investigación №1605003, 2016. Una versión muy preliminar del presente texto, fue publicada por Espinosa y Alarcón (2017). 
Bancarización en base al Negocio del Barrio:

\section{El Caso CajaVecina}

1 presente capítulo busca mostrar un caso de cambio tecnológico que se alinea con el fenómeno conocido como 'Cashless Society'. Como lo ha mostrado Hernández et al. (2012) para el caso chileno, diversos actores de la industria bancaria y de pagos han buscado construir nuevos canales de pagos para la población no bancarizada de Chile. Dentro de las alternativas se encuentran las corresponsalías como la CajaVecina. Dichas corresponsalías, impulsadas por una entidad bancaria llamada BancoEstado- tendrían un costo por transacción menor que las oficinas bancarias. Este costo es incluso menor que el que conlleva la operación de Cajeros electrónicos -ATMs, pero mayor que canales alternativos basados en internet y telefonía móvil. La CajaVecina en este sentido, se define como:

un canal de atención para los clientes y no clientes de BancoEstado, que funciona en locales comerciales, durante sus horarios de funcionamiento. A través de terminales instalados en los almacenes, permite realizar una serie de transacciones bancarias y servicios financieros, utilizando las tarjetas de cajeros automáticos BancoEstado o la tarjeta de débito de Cuenta RUT' (Gobierno de Chile, 2013, p. 41)

El citado informe, da cuenta además de que la CajaVecina permite realizar servicios de: retiros de dinero, depósitos en efectivo, transferencias entre cuentas BancoEstado, consultas de saldo, pagos de créditos y dividendos, pago de servicios, avance y pagos de tarjeta de crédito BancoEstado y recargar el teléfono móvil, entre otros. La tecnología que permite las transacciones es un terminal POS - point of sale, por su denominación en inglés- que se comunica con el sistema central del banco.

El mecanismo de inclusión financiera de la CajaVecina, ha tenido el soporte de una innovación relacionada, la llamada cuenta RUT. Esta cuenta vista, también operada por BancoEstado, posee más de siete millones de tarjetas emitidas. La citada cuenta vista, se apertura en forma automática en base al rol único nacional, es decir, 
el documento único para certificar la identidad natural y/o tributaria de cada persona en Chile. Es así como el usuario accede a la red de cajeros automáticos y a los dispositivos electrónicos autorizados por la entidad reguladora del sector bancario Chileno. El procedimiento de la apertura de la Cuenta RUT es sencillo, no requiere que se acredite renta ni antecedentes comerciales.

Respecto de la regulación del sistema, un reporte realizado por el Programa Tec-In (2013) ha mostrado que la normativa aplicable a las corresponsalías en Chile es del tipo tangencial. De hecho, la referencia legal es mínima, contemplándose sólo un anexo en el capítulo 20 de la recopilación actualizada de Normas de la Superintendencia de Bancos e Instituciones Financieras -SBIFsobre tercerización de servicios. Aún más, el reporte muestra que el concepto 'corresponsal' ni siquiera es nombrado en el cuerpo de dicha ley. Este es entonces un caso de inclusión financiera con escasa regulación.

El Gobierno de Chile (2013) ha planteado que el modelo de negocios de la CajaVecina es atractivo tanto para el comerciante como para el BancoEstado. El Gobierno asegura que flujo de clientes del almacén aumentará y éste recibirá comisiones por la prestación del servicio a clientes del Banco. La adopción de la innovación es refrendada por la Asociación de Bancos e Instituciones Financieras -ABIF- que ha cuantificado el crecimiento de las corresponsalías en el Gráfico No 1. De hecho, el número total de corresponsalías en Chile ha presentado un explosivo crecimiento entre el 2006 y marzo del 2015. Al 2015, la CajaVecina posee alrededor de un 40\% del mercado de corresponsalías de Chile. 
Gráfico 1

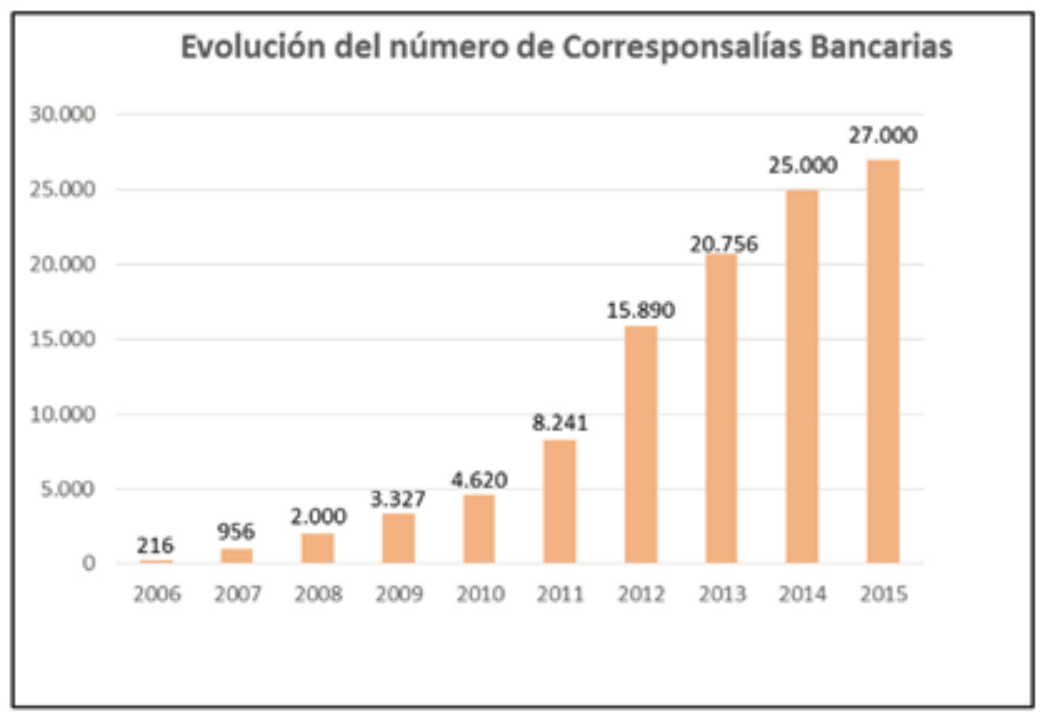

Source: Chilean Banks Association and SBIF

Este cambio abrupto puede ser observado desde múltiples ópticas. Por un parte, se puede apreciar un criterio de éxito de inclusión financiera basado puramente en la adopción de la corresponsalía (Gobierno de Chile 2013). No obstante, este discurso encubre la compleja relación entre los usos del dinero y el proceso de bancarización de la vida cotidiana de los usuarios y otros actores involucrados (Wilkis, 2013b). La apuesta del proyecto invita a pensar las reconfiguraciones entre el pago y banca que personas pueden acceder en sus almacenes que podrían afectar la cultura entera de la vida económica de las personas en Chile.

Múltiples investigaciones han dado cuenta de los cimientos culturales que se encuentran detrás de los fenómenos de bancarización, ya sea las transformaciones no solo políticas y económicas, sino que también en los mecanismos de ahorro e inversión tras la crisis del “Corralito" en Argentina (Luzzy, 2008) o transformaciones del en las rutinas de ahorro, inversión y crédito en Chile con la masificación de la banca y crédito en las últimas décadas (Ossandón, 2012). En ello, el proyecto busca ampliar la comprensión actual del "ecosistema de 
pago" alrededor de la Caja Vecina, en donde interactúan almacenes, almaceneros y usuarios. Para ello, se plantea comenzar desde las comprensiones de los actores, rescatando sus concepciones de los usos, con el fin de entregar una mirada cualitativa sobre los orígenes, límites y potencialidades de este servicio.

Para acercarse a un análisis más complejo de éste mecanismo de inclusión financiera será entonces necesario introducir algunos conceptos que provienen de la sociología del dinero, del crédito y de los estudios organizacionales. Luego de ello, se realiza un análisis de un corpus de datos proveniente del sitio www.reclamos. cl. En éste web site diversos usuarios expresan los problemas que han encontrado en el uso del sistema CajaVecina (entre otros). Es a partir de la categorización de dichos reclamos que se analizarán aspectos centrales de la institucionalización y de la CajaVecina como un dispositivo que afecta la ecología de los pagos, las relaciones económicas entre los usuarios, además de afectar también a los comerciantes que actúan como corresponsalías del Banco.

\section{REVISIÓN DE LA LITERATURA}

\section{La Mirada Sistémica y CUlturalista Del Dinero}

El dinero para la economía moderna no se entiende sin sus tres propiedades: contabilidad, valor e intercambio (Samuelson, 2003). Este hecho ha sido asimilado de las ciencias sociales al punto que Habermas (1987) lo considera un mecanismo a-social por excelencia que deviene a de los procesos de integración sistémica. En ello, Parsons (1970) y Luhmann (2006) comienzan la problematización del dinero como un medio de comunicación simbólicamente generalizado que solo tiene cabida en los respaldos de una teoría de la comunicación, en donde el dinero comunica expectativas y atribuciones tanto para ego/alter.

El dinero, se ha estudiado sociológicamentey antropológicamente. En particular, algunos teóricos han estudiado la evolución de los procesos de diferenciación social. No obstante, el recorrido histórico del dinero ha sido propuesto por la economía sustantivista de Polanyi (2006), estableciendo que no se puede esgrimir una teoría 
inequívoca sobre los usos del dinero, pues en la antigüedad, el dinero compartía su función de intercambio económico como la reciprocidad y redistribución. De hecho, considerando el dinero como medio de comunicación simbólicamente generalizado, Luhmann $(2007 ; 2013)$ desentrańa lo que otros intelectuales ya habían concebido: la objetivación, socialización y universalización del dinero al punto de ser concebido como un soporte a-social (Hopenhayn, 2002; Simmel, 2013; 2010). En dicho sentido, el dinero permite aumentar la probabilidad de la comunicación, donde se facilita la comprensión y el proceso de selección o exclusión entre el oyente y el hablante. Como consecuencia, al facilitar los medios de pago y al actuar como mediadora en el proceso de uso del dinero por parte de sus usuarios, el mecanismo que se ha creado con la corresponsalía chilena de la CajaVecina se puede entender como un objetivizador de la comunicación en el sistema económico.

Como objetivador económico, el dinero es un reductor de complejidad. Es decir, el dinero permite que en los sistemas de interacción se coordine las complejas relaciones que emergen en las comunicaciones de la esfera económica (Luhmann 2007; 2013). No obstante, al teorizar de dicha manera el dinero, Luhmann elimina el poder agencial del mismo, poder que ya había sido establecido por autores como Simmel. Para superar éste problema, Zelizer (2011) profundiza en los significados atrapados del dinero, desarrollando los procesos de calculabilidad social y económica que los agentes establecen al relacionarse por el dinero y medios de pago. De ésta manera, Zelizer desbarata la muralla impuesta entre las ciencias sociales y económicas para estudiar éste tipo de medio de pago.

De hecho, Zelizer señala que el dinero, y por ende los medios de pago que intervienen en el uso y digitalización del mismo, permiten a los individuos 'marcar' las relaciones sociales y las económicas. Por ende, el dinero como soporte, no está libre de los alcances y limitaciones sociales, sino que mediante el dinero los individuos generan procesos objetivadores de la moneda, pero además, crean, mantienen o disuelven vínculos sociales, además de controlar y establecer desigualdades. Los individuos marcarán así estatus, 
manejarán la incertidumbre, y administrarán su intimidad.

Considerando el análisis de Zelizer es entonces fundamental comprender la CajaVecina como una innovación en la que se crean, mantienen y controlan vínculos sociales y en donde la economía se funde en una mixtura con éstos procesos complejizándose la relación entre los actores que participan. Este aspecto entrecruza las relaciones sociales, al punto que Zelizer (2011) entiende que no hay una separación entre los mundos afectivos y económicos, los dos se entrecruzan, rechazado la hipótesis diferenciadora la sociedad bajo la figura de los "mundos opuestos". Esta dimensión relacional de la que da cuenta la autora más la dimensión comunicacional de la que da cuenta Luhmann (2007), son en conjunto condiciones necesarias pero no suficiente para comprender el fenómeno de la CajaVecina. Para profundizar en el análisis de éste particular fenómeno, se introducirán algunos conceptos claves acerca de la bancarización de la vida cotidiana, mismos que complementarán la dimensión de agencialidad y de coordinación comunicacional en lo económico de la CajaVecina.

\section{Sociología de la BanCARIZación y el CRÉdito}

Existen diferentes aproximaciones para acercarse a los fenómenos de inclusión financiera que han sido llamados de bancarización. En el presente escrito, se entiende que la bancarización de la vida cotidiana guarda relación con los procesos históricos que han sufrido las operaciones financieras de crédito y pago en el día a día de las personas. Desde dicha perspectiva, Wilkis (2013a) comenta que las familias populares argentinas, se ven redefinidas en su calidad de actores por la extensión del mercado al crédito y el mundo del consumo. Esta transformación no se basa en la lógica vertical de un modelo que busca generar el advenimiento de un homo economicus (Wilkis, 2014). Más bien, sobrelleva la generación de actitudes de reciprocidad inter/extra familiar como la sobrevivencia del colectivo, concibiendo nuevos actores empoderados como las dueńas de casa -matriarcado presupuestario-, quienes detentan el pasado, presente y futuro del capital moral en la gestión de las cuentas, regulando 
mediante acuerdos informales quién entra, sale y se mantiene en la red social (Wilkis, 2013a). En el mismo sentido, Ossandón (2014) comparte que analizar la bancarización de la vida cotidiana entregaría nociones en la comprensión de nexos entre inclusión/ exclusión financiera. Ossandón (2014), ha mostrado que la gente en Chile se presta las tarjetas de crédito, o más precisamente se presta los límites de crédito otorgados. Es de ésta manera que las relaciones sociales aparecen parasitando al crédito y complejizando las relaciones económicas relacionadas con la bancarización y el crédito.

Wilkis (2013b), resalta que en Buenos Aires la bancarización ha generado actitudes de reciprocidad inter/extra familiar en la lógica de sobrevivencia del colectivo, concibiendo nuevos actores empoderados como las dueñas de casa -matriarcado presupuestario-, quienes detentan el pasado, presente y futuro del capital moral en la economía doméstica, regulando mediante acuerdos informales quién entra, sale y se mantiene en la red social (Wilkis, 2013b). No obstante, el relato no sólo está acompańado de "ganancias sociales", pues los actores a la vez, se ven afectados por niveles de ansiedad e intranquilidad generados por las deudas que vienen dadas por el acceso a productos bancarios, comprometiendo altos niéveles de confianza y tensiones para mantener su conexión con el mercado crediticio.

Ossandón (2012; 2014) localiza conclusiones similares que Wilkis, denunciando que detrás de los estudios sobre bancarización y más en general sobre inclusión financiera, se ha puesto un mayor énfasis en el impacto de cobertura del proceso más que su carácter y la complejidad social emergente del mismo. El ejemplo estudiado por Ossandón (2014) ha demostrado que la utilización de tarjetas de crédito del retail -comercio detallista- chileno genera lo que el sociólogo llama "economías del cupo". Dicho tipo de economía se sostiene en circuitos económicos que apelan a los mismos principios solidarios de las cooperativas de ahorro. Es por ello, que en dicho proceso, se visualiza un doble aprendizaje colectivo, ya sea de la estructura crediticia al enfrentarse como consumidores, y una 
versión de lazos de confianza/desconfianza de sus redes y capitales sociales próximos. En este ejercicio la calculabilidad, el actor se operacionaliza no solo el beneficio común, sino que además, busca mantener y aumentar los cupos como beneficio del cumplimiento sistemático del pago -la extensión del cupo entendido como la siembra financiera- y el acceso a beneficios institucionales como mecanismos de propaganda institucional para el uso de estas cuentas -regalos, cupones o puntos canjeables-.

\section{La CajaVecina como Isomorfismo Organizacional}

Por otro lado, y desde la corriente neo-institucionalista de la teoría organizacional, se apela a los fenómenos de rediseño, performatividad y asimilación de las prácticas expertas bancarias. El neo-institucionalismo entenderá los procesos de bancarización como desarrollados por los bancos y asimiladas por los almacenes, creando fenómenos de convergencia, conflicto y nuevas racionalidades. En dicho sentido, DiMaggio y Powell (1983) destacan que las organizaciones generan procesos de homogenización en sus estructuras y prácticas. Es decir, cuando las organizaciones poseen un mismo rubro, se abren procesos de asimilación y mimetización que pueden ser pensados en tres caminos diferentes pero no excluyentes, y que para el caso bancario se sintetizan en:

a) Coercitivo: la asimilación de prácticas bancarias por organizaciones que históricamente no habían sido consideradas de esa manera.

b) Mimético: ya sea, por novedad u registro de éxito, las organizaciones pueden estar abiertas a incorporar cambios en su organización.

c) Normativo: no obstante, los cambios coactivos y miméticos llegan a las organizaciones a socializarse con artefactos y formas de lógicas propias de la organización bancaria, tal como los dispositivos y rutinas bancarias

La imposición entonces de una la adaptación en forma continua de las organizaciones en un contexto de ampliación de mercado y a la provisión de bienes y servicios, la llamada population ecology 
(Hannan y Freeman, 1986) permitirá entonces un entorno de servicios bancarios según el contexto de adaptación, donde se distinguen dos tipos:

a) Las organizaciones generalistas, que este caso serían los almacenes que no se hacen parte del proyecto CajaVecina

b) Las organizaciones especialistas, como los almacenes que están dispuestos a cambiar, introduciendo elementos que van en favor de su foco de experticia, en este caso, la introducción de nuevos elementos que les permiten mantenerse al día y según la población organizacional.

\section{Metodología y CoRpus de dATOS}

La investigación se entabla bajo el paradigma comprensivo (García, 2003), pues la realidad de la cual se quiere dar cuenta se expresa mediante acciones y lenguajes de los actores, que acuden a los mismos con el fin de expresar sus propios procesos de subjetividad. Por otro lado, se considera no reducir la realidad a variables, sino que más bien a fenómenos que se están manifestando como un todo integral, auto-organizado, y con sus propias significaciones en donde los investigadores en base a sus propios conceptos y visión de mundo pueden acceder a la misma. De esta manera, el conocimiento alcanzado será trabajado desde la internación de la realidad elegida para forjar el conocimiento.

El corpus de datos se obtuvo del sitio web: www.reclamos.cl. Como estrategia, se codificó de manera inductiva y emergente. Atlas. ti 7.5 facilitó la elaboración de códigos aglutinadores de carácter exploratorio mediante dos principios metodológicos: generalidad semántica y mutua exclusión. Así, entonces, se establecieron cinco códigos según la información entregada por el marco teórico y los discursos de los actores.

La unidad de análisis fue construida desde los reclamos, considerados como casos analíticos. En los reclamos, se diferencian dos tipos de usuarios: a) el usuario regular del servicio de CajaVecina, entendido como el sujeto bancarizado; b) el actor intermediador entre el cliente y el banco, caracterizado por dueños y/o gestor del 
local comercial. La codificación de los datos ha sido emergente, dando cuenta de una lectura global de los reclamos. De manera emergente, se han elaborado códigos aglutinadores de carácter exploratorio, considerando dos principios metodológicos: principio de generalidad semántica y mutua exclusión -exhaustivo (Cáceres, 2008). En cuanto al análisis, el material codificado, se analizó en cuanto a su contenido.

Con el fin de proporcionar grados de confiabilidad a la investigación, se ha destinado trabajar con dos tipos de triangulaciones al momento de obtener los datos: a) triangulación de investigadores (Okuda y Gómez, 2005) estableciendo que el equipo de investigación estará volcado en su plenitud a la búsqueda, análisis, constatación teórica y nuevos hallazgos; b) triangulación teórica (Stake, 1998) al sostener que la existencia de "realidades múltiples" en el desarrollo de una investigación contempla la confluencia de diversos actores que expresas sus opiniones, discursos y enunciaciones acerca del problema de investigación propuesto. Los anteriores, pueden ser actores cotidianos, investigadores y teóricos que triangulan la información y conocimiento que rodea, comprende y explica la problemática que aborda este diseño. Por ende, esa información que se comienza a gestar como similar es triangulada dando veracidad a los conceptos, técnicas de recolección y análisis generados en el transcurso de esta investigación. Todos los testimonios de reclamos han conservado la grafía original, para no alterar el corpus.

\section{Resultados y Discusión}

Según los datos recabados, el sujeto que habla sobre CajaVecina tiende a visualizar el almacén como una sucursal bancaria. Dicha sentencia se realiza, pues los clientes buscan mediante la página web -reclamos.cl-, dar cuenta prioritariamente de una serie de operaciones financieras fallidas. Dichas operaciones, que si bien, están incluidas al interior del sistema de CajaVecina, no logran finalizarse por una serie de fenómenos, ya sea el desconocimiento del procedimiento, problemas de señal del POS y/o la inexperiencia del almacenero al usar el sistema. 
Los "errores de pago", tal como son sentenciados por los clientes, generan un sentimiento de disconformidad, pues ellos plantear no solo perder dinero, sino que también tiempo en la gestión de la operación comercial, aludiendo a las problemáticas presentadas por los usuarios del servicio de Caja Vecina, quienes al momento de pagar sufren dificultades de sincronización entre los niveles macro -empresa prestadora/oferente de servicios-, meso - uso del Servicio Caja Vecina- y micro -entendimiento distorsionado y/o conflictivo, dado el uso de intermediarios.

Este aspecto es de importancia, pues radica en el hecho que los clientes no focalizan sus reclamos al sistema de CajaVecina, sino que a su intermediario directo asemejado en la figura del almacenero. Esto se relaciona con un intento de asimilación vertical, del que dan cuenta Wilkis (2014) y desde el punto de vista organizacional y en el trabajo de DiMaggio y Powell (1983). Cuando la política bancaria decide ampliar sus operaciones, considera otros actores que son catalogados como "intermediarios", siendo dotados de implementos -POS- y una red -señal telefónica-, para que puedan actuar en la ampliación del sistema bancario y las operaciones comerciales anexas.

Por lo tanto, con los los errores de pago, CajaVecina deja de ser definido como elemento facilitador. Pues al abrir el servicio para intermediar en el pago de un servicio, el cliente posee una lógica de comparación, en el sentido que en los "tradicionales" centros de pago, el mismo podía tener certeza que las operaciones realizadas serán exitosas, no sucediendo lo mismo en los almacenes, tal como lo señala la siguiente cita:

"Compre un seguro automotriz y me explicaron que tenía que descargarla de la página caja vecina y la pagina no funciona, quién me devuelve mi dinero" (Reclamo No16)

Desde el problema de la operación del sistema, los autores se plantean la pregunta sobre la existencia de distinciones entre el servicio en oficinas tradicionales del BancoEstado y aquellas que se pueden realizar desde la CajaVecina. En dicho sentido, la facilitación puede comprometer la oferta de servicio que el dueńo del sistema 
-BancoEstado- realiza. Lo cual lleva a profundizar sobre el problema de la integración de éstos servicios (Wilkis, 2014) y a analizar cómo es que el banco atiende el problema que se produce al comparar servicios prestados por entidades relacionadas que utilizan claras estrategias de segmentación entre un servicio más tradicional, como son las oficinas comerciales del propio banco. En ésta distinción, plantean los autores, existe un importante fenómeno que debe ser analizado con mayor profundidad.

Al parecer, estos procesos se originan debido a una falta de socialización efectiva del sujeto intermediario que opera la CajaVecina y el cliente del BancoEstado en la misma. Es interesante entonces que BancoEstado deriva los reclamos generados por los mismos almaceneros operadores de CajaVecina, clasificándolos como "problemas técnicos en la mantención del servicio de CajaVecina", asociados a los procesos propios de comunicación de información del sistema entre el Banco Estado y el almacén. En ésta categoría, se sintetizan los reclamos asociados a la falta de mantención y procesos de coordinación, generando dos problemas a nivel "mimético organizacional": a) la interrupción del servicio, estableciendo molestias para el usuario del servicio e intermediario; b) molestia por parte de los almaceneros(as) por no recibir un acompañamiento para velar por el correcto uso del servicio de Caja Vecina, como por ejemplo en el siguiente caso:

"Encuentro que es un falta de respeto que en 10 dias nadie de Caja Vecina o del banco sean capaz de darle solución al problema, o que no allá ninguna persona que dé, la cara del banco. Al aparecer de los del banco no se dan cuenta de las molestia que nos ocasionan a nosotros con nuestros clientes y las personas que realizan transacciones en mi local" (Reclamo No22).

No obstante, no todos los procesos aluden a los problemas técnicos y coordinación. Como lo menciona Wilkis (2014) el almacenero se empodera en el avance en la bancarización de la vida cotidiana, pero ya no vista desde los procesos verticales, aludidos a la figura del intermediario pasivo, que gana una comisión por el número de transacciones generadas. Para comprender dicho proceso, se puede 
observar la categoría: "mala atención de almacenero", la cual alude a las reclamos presentadas por los clientes que destacan un trato indecoroso y sesgado por parte de la CajaVecina. Se observa por una parte, el ideal normativo de equiparar y asimilar el almacén como una sucursal exclusiva del banco, aludiendo a formas de trato del cliente, horarios y disponibilidad del servicio. No obstante, en una segunda instancia, se presenta el hecho que el almacenero es dueño y/o administrador de su emprendimiento económico, y que en dicho camino ha generado principios propios de gestión y desarrollo de su almacén.

Cruzando ambos principios, se observa que ideal intermediario no se concreta, dado la utilización de criterios por parte del almacenero que ponen en juego otras formas de distinción en la atención al cliente, ya sea la proximidad social-grados de confianza y amistad- y su propia rentabilidad económica. El efecto de la proximidad social se puede ver en el siguiente caso:

"Se ve claramente que solo acepta a algunas personas ya que mi esposa le hizo un reclamo de esa situación. Ahora que se necesita realizar algún trámite no lo permite esta persona (...)" (Reclamo No12).

Dicho nivel de agenciamiento no solo se puede observar en el trato directo del cliente, sino también en la administración local de la CajaVecina. Por política del BancoEstado, las CajaVecina manejan fondos limitados para la gestión de transacciones económicas, fondos que pueden ir en aumento según el tiempo transcurrido y la morosidad del cliente, tema asociado a los mecanismos de siembra descritos por Ossandón (2014). Dicho mecanismo de siembra, coloca a la escasez en un orden prioritario en la administración de la CajaVecina.

El agente operador de la CajaVecina gestiona en base a la existencia de fondos que le otorga la administración central de CajaVecina. Ésta, se convierte en variable fundamental para dar servicio a los usuarios/clientes del sistema, pues establece un máximo de fondos con los cuales el almacén puede dar respuesta.

Es por ello, que se observa un dilema, pues la la escasez de siembra es traducida en falta de liquidez para las transacciones cotidianas. 
Los clientes clientes perciben este problema, siendo asociado como la "falta de saldo en CajaVecina". Con ello, se observa, una vez más, un usuario que desea asimilar a la CajaVecina con una sucursal bancaria. Pues, los usuarios hablan de la ineficiencia del servicio, que no cumple su promesa de representar un banco más próximo a la figura del cliente, tal como se presenta a continuación:

"Cada vez que intento hacer algún retiro en cajas vecinas en la comuna de la florida me dicen siempre que no tienen saldo a la hora $q$ sea me dicen lo mismo y me veo obligada a ir a hacer colas interminables de los bancos" (Reclamo No2).

El reclamo $\mathrm{N}^{\circ} 2$, muestra que los clientes advierten un segundo momento, ya que toda falta de liquidez viene asociada a prácticas de gestión de la misma. Cuando el usuario advierte que el almacenero tiende a privilegiar el servicio a ciertos clientes -por lo general más próximos-, como también colocar "arbitrarios" montos mínimos y máximos para la gestión de las operaciones económicas, se manifiesta que el almacenero posee formas de atención anteriores y que no corresponden necesariamente con los principios de la política de BancoEstado. Frente a una nueva herramienta de atención de clientes, el almacén no genera una división en la gestión de sus productos tradicionales y la CajaVecina, siendo operado bajo una cláusula en donde se le reservan productos y servicios a los clientes según su grado de conocimiento, confianza y lealtad al emprendimiento. Dicho evento, a juicio de los clientes degradados, no sucede en las tradicionales casas bancarias, pues la "cola -fila de atención- del banco" es lo que dibuja la igualdad, como también el reclamo frente al intermediario.

Las categorías analizadas, se encuentran íntimamente relacionadas con el servicio que presta el sistema CajaVecina. Como un todo, se observa en el corpus de reclamos.cl, que si bien los usuarios consideran beneficioso el servicio de CajaVecina, el mismo sería oneroso, dado el costo por uso de servicio, mismo que asciende a 0,5 dólares aproximados por cada transacción. La comparación que cualquier usuario puede realizar, guarda relación con el cobro que se genera al utilizar las dependencias bancarias tradicional versus 
utilizar CajaVecina. Se observa entonces un costo adicional. El costo extra, unido a las categorías por problemas de servicio, muestra una controversia no cerrada en la bancarización del día a día de quienes utilizan el servicio de la CajaVecina.

Sin embargo, también se puede apreciar que el almacenero se une a esta política de cobro, entendiendo que él no solo debe generar una rentabilidad económica a raíz de las comisiones por las transacciones realizadas, sino que también cobrar un monto arbitrario por la gestión de los servicios a los clientes. Dicho pago, tal como es mencionado por los clientes, es directo y presencial al momento de consultar por una operación:

"Además de donde se puede reclamar por el cobro de seudo-comisión que se auto-imponen para pagar una cuenta o depósito me ha tocado un negocio que cobra $\$ 100$ por cada pago de cuenta y otro quiero realizar un depósito a una cuenta Rut y me cobraba \$500 por el depósito" (Reclamo No22).

Con ello, se menciona que el paso de un nivel de intermediación hacia uno agencial, no solo comprende la innovación en materia de gestión y clasificación de los clientes, sino que además elementos en donde se podrán llevar hasta relativizar los principios de operación de la Caja Vecina. Esto sucede a pesar de que existen acuerdos entre quienes operan el sistema y la administración central de CajaVecina. Es así como podemos comprender que el espacio de pagos y de operaciones financieras ligadas a la CajaVecina 'no es sólo una heurística conceptual de personas en la industria, el sector público, y la sociedad civil en general...sinó que es también un territorio' (Maurer, 2008, p. 2). El sistema de la CajaVecina es sin duda un territorio en donde los almaceneros intermediarios se convierten en parte fundamental de la manera en la que la institución financiera implementa el mismo. En éste caso, una implementación en donde la flexibilidad que éstos tienen, permite una variedad de experiencias para con el usuario.

Conclusiones y Futuros Estudios

El presente artículo se adentra en un aspecto del mecanismo de 
inclusión financiera llamado CajaVecina. El sistema en cuestión, amerita ser analizado de manera más detenida que la sólo ofrecen los datos sobre difusión y adopción del mismo. Si bien dichos datos muestran un crecimiento importante de éste tipo de corresponsalías, luego del análisis de los reclamos y su categorización, se puede hipotetizar que la CajaVecina es un caso complejo de isomorfismo organizacional y que posee varias capas, mismas que deben revelarse cuidadosamente para llegar a una comprensión más acabada del mismo.

Tal como lo comentara Bergoeing (2013), medir la inclusión financiera que conlleva la innovación de la CajaVecina, presenta un sesgo que no deja ver aspectos tales como el elevado costo de la misma, los problemas socio-técnicos que ésta trae aparejados, y por sobre todo, el efecto de la proximidad social relacionados con intermediario entre el banco y el usuario. El caso permite apreciar que la política del BancoEstado, respecto al manejo de CajaVecina, entra a convivir con otras lógicas de gestión y administración de almacenes. Estos procesos, si bien no entran en contradicción con la administración de la política, la complejizan introduciendo dimensiones creadoras de conflictos y desencuentros.

Comprendiendo la CajaVecina como una organización, y siguiendo el análisis del trabajo del nuevo institucionalismo (DiMaggio y Powell, 1983) y de la ecología de las poblaciones organizacional (Hannan y Freeman, 1986) se concluye del análisis del set de reclamos que la innovación realizada con el sistema de la CajaVecina no es totalmente mimética respecto de su contraparte tradicional bancaria. Muy por el contrario, esta es una adaptación donde el mecanismo de inclusión financiera permite que los almacenes se transformen en especialistas (Hannan y Freeman, 1986). Dicha especialización es sin embargo con cargo a una permanente comparación que realiza el usuario respecto de la prestación de servicio de la CajaVecina versus la entregada por por las sucursales del Banco. Dicha comparación, se hace patente cuando se observa que los usuarios realizan sus reclamos al almacenero que opera como intermediario la CajaVecina y no a la administración central 
de CajaVecina y/o al BancoEstado. Con todo, comprender que la CajaVecina es un intento de asimilación vertical y las diferencias operativas que observan los usuarios en el set de reclamos analizados no es suficiente para dar cuenta de la pregunta del presente texto.

Los autores postulan que lo que se deja entrever en el análisis de los reclamos es una figura de almacenero que intentará llevar adelante sus objetivos en desmedro de un usuario que busca un servicio al menos similar al que podría obtener en las oficinas del banco. Es desde dicha comprensión que se puede avanzar con la pregunta, ¿qué tipo de mecanismo de inclusión es el que conlleva la CajaVecina? En primera instancia, se puede hipotetizar que uno muy distinto al que se otorga a quienes tienen acceso al BancoEstado en sus oficinas y a aquellos que tienen el beneficio de poseer una cuenta distinta a la cuenta RUT. Es decir, quienes representan el segmento de usuario que mayoritariamente utiliza los servicios de la CajaVecina. Con ello, podríamos decir, junto a Maurer (2008) que la CajaVecina, transforma el 'espacio de los medios de pago' de una manera innovativa. Una posible explicación de ésta transformación, se encuentra en la flexibilidad que otorga BancoEstado para que el intermediario que opera el sistema, sea en parte el dueño del espacio de pagos.

No obstante, para trascender lo aquí explicado se deben forjar nuevas investigaciones que continúen problematizando las percepciones sobre continuidades y agencias de la política de CajaVecina. Si bien el presente escrito se centró en los reclamos de los clientes, también se hace necesario el rescate de los planteamientos de los mismos almaceneros que participan día a día no solo en la difusión del sistema de CajaVecina, sino que también en su constante ampliación. Esto, por ejemplo, también permitiría estudiar el isomorfismo organizacional -en sus aspectos miméticos- para los almacenes especialistas que operan CajaVecina y para aquellos que no lo hacen.

Un último elemento tiene que ver con las trayectorias macronacionales en los proyectos de inclusión financiera. Frente a ello BatizLazo y Efthymiou (2017) han recopilado un número no menor de 
sistemas de pago alrededor de accidente, y principalmente enfocado en economías del sur. En ello, sería pertinente ver posibilidades de comparación, guardando las innovaciones nacionales, para dar cuenta de un estado del arte en materia de inclusión financiera, rescatando políticas exitosas, desafíos y posibilidades de innovación.

\section{BIBLIOGRAFÍA}

BATIZ-LAZO, B. \& EFTHYMIOU, L (Eds.). (2016). The Book of Payments: Historical and Contemporary Views on the Cashless Society. Palgrave Macmillan: United Kingdom. http://doi. org/10.1057/978-1-137-60231-2

BERGOEING, R. (2013). Mesa Redonda: Banca Corresponsal y Cuentas Simplificadas ASBA - FOMIN/BID, 26 de julio de 2013, Washington DC, EE.UU. Banca CorresponsalReflexiones desde el Outlier. Disponible en: http:// www.cronologiabancaria.cl/sbifweb3/internet/archivos/ DISCURSOS_10299.pdf

D`AVELLA, N. (2012). Pesos, dólares y ladrillos: la especialidad del ahorro en Argentina. Boletín de antropología, 44 (27), 127-143. Disponible en: http://www.redalyc.org/articulo. oa?id $=55726909007$

CÁCERES, P. (2008). Análisis cualitativo de contenido: Una alternativa metodológica alcanzable. Psicoperspectivas. Individuo y Sociedad, 2 (1), 53-82. Disponible en: http:// www.redalyc.org/articulo.oa?id $=171018074008$

DIMAGGIO, P. \& POWELL, W. (1983). The Iron Cage Revisited: Institutional Isomorphism and Collective Rationality in Organizational Fields. American Sociological Review, 48, 147-160. Disponible en: https://www.jstor.org/ stable/2095101?seq=1\#page_scan_tab_contents

ESPINOSA, J, \& ALARCÓN, J. (2017). CajaVecina: The Bancarization of Chile through Corner Shops. BATIZ-LAZO, B. \& EFTHYMIOU, L. (Eds.). The Book of Payments: Historical and Contemporary Views on the Cashless Society, 
141-151. http://doi.org/10.1057/978-1-137-60231-2

GARCÍA, J. (2003). Ciencias humanas, post-fundacionalismo y post-representacionalismo. Santiago de Chile: Universidad Academia de Humanismo Cristiano.

GOBIERNO DE CHILE. (2013). Informe Inclusión Financiera y Medios de Pago Electrónicos. Ministerios de Desarrollo Social, Economía, Hacienda y Transporte y Telecomunicaciones. Disponible en: http://www.economia.gob.cl/wp-content/ uploads/2014/04/Informe-Inclusi\%C3\%B3n-Financiera-yMedios-de-Pago-Electr\%C3\%B3nicos.pdf

HERNÁNDEZ, C. MAINO, M. \& VILLAR, C. (2012).

Masificación de los medios de pago: Barreras de adopción de la tecnología financiera. Documento de Trabajo. Santiago de Chile: Facultad de Economía y Negocios UNAB.

HABERMAS, J. (1987). La teoría de la acción comunicativa II: crítica a la razón funcionalista. Madrid: Taurus.

HERNÁNDEZ, C. MAINO, M. \& VILLAR, C. (2012). Masificación de los medios de pago: Barreras de adopción de la tecnología financiera. Working Press Santiago de Chile: Facultad de Economía y Negocios UNAB

HOPENHAYN, M. (2002). El mundo del dinero. Buenos Aires: Norma.

LUHMANN, N. (2007). La sociedad de la sociedad. México D.F: Herder y Universidad Iberoamericana

LUHMANN, N. (2013). La economía de la sociedad como sistema autopoiético. MAD, 29, 1-25. http://doi.org/10.5354/07180527.2013 .27342

LUZZY, M. (2008). Las instituciones bancarias cuestionadas: actitudes y representaciones de los ahorristas frente a los banco de la crisis del 2001 en Argentina. Crítica en desarrollo, 2 (2), 172-190. Disponible en: https://www. academia.edu/3597459/_La_instituci\%C3\%B3n_bancaria_ cuestionada_Actitudes_y_representaciones_de_los_ ahorristas_frente_a_los_bancos_en_el_contexto_de_la_crisis_ de_2001_en_Argentina_ 
MAURER, B. (2008). Retail Electronic Payments Systems for Value Transfers in the Developing World. Working Press, disponible en:https://www.semanticscholar.org/paper/Retail-ElectronicPayments-Systems-for-Value-Maurer/1ee6b07f070a5b6cfab2 $1798 \mathrm{a} 92 \mathrm{~b} 829 \mathrm{a} 4831032 \mathrm{~b}$

OSSANDÓN, J. (Ed.). (2012). Destapando la caja negra: sociologías de los créditos de consumo en Chile. Santiago de Chile: Universidad Diego Portales. Disponible en: http:// www.icso.cl/noticias/destapando-la-caja-negra-sociologia-delos-creditos-de-consumo-en-chile/

OSSANDÓN, J. (2014). My Story Has No Strings Attached: Credit Cards, Market Devices, and a Stone Guest. Working Press. Disponible en: http://www.imtfi.uci.edu/files/blog_working_ papers/2014-3_Ossandon_Working\%20Paper\%202.pdf

OKUDA, B. \& GÓMEZ, C. (2005). Métodos en investigación cualitativa: triangulación. Revista Colombiana de Psiquiatría, XXXIV (1), 108-124. Disponible en: http://www.redalyc.org/ pdf/806/80628403009.pdf

PARSONS, T. (1970). Some Problems of General Theory in Sociology. En: MACKINNEY, J. \& TIRYAKIAN, E. (Eds.) Theoretical Sociology: Perspectives and developments. New York: Appleton-Century, 27-68.

POLANYI, K. (2006). La gran transformación: los orígenes políticos y económicos de nuestro tiempo. México: Fondo de Cultura Económica

PROGRAMA TEC-IN (2013). Banca Corresponsal e inclusión. Disponible en laf.com/mehttp://www.caf.com/ media/1634561/01_informe_marcos_regulatorios_cnb.pdf SAMUELSON, P. (2003). Economía. México: McGraw Hill. SIMMEL, G. (2003). Filosofía del dinero. Granada: Comares. SIMMEL, G. (2010). Cultura liquida y dinero. Fragmentos simmelianos de la modernidad. México: Antrhopos.

STAKE, R. (1998). Investigación con casos de estudio. Argentina: Morata.

WILKIS, A. (2013a). Sociología del crédito y economías de las 
clases populares. Revista Mexicana de sociología, 17 (2), 235-252. Disponible en: http://www.redalyc.org/articulo. oa?id $=32130485004$

WILKIS, A. (2013b). Las sospechas del dinero: moral y economía en la vida popular. Buenos Aires: Paidós.

WILKIS, A. (2014). Una sociología moral de las relaciones bancarias. Desacatos, 44, 210-215. Disponible en:

http://www.scielo.org. $\mathrm{mx} /$ scielo.php?script=sci_arttext\&pid =S1405-92742014000100015

ZELIZER, V. (2011). El significado social del dinero. México: Fondo de Cultura Económica.

Fecha de Recepción del Artículo: 19 de marzo de 2017 Fecha de Aceptación: 13 de mayo de 2017 